\title{
Creating Characters in a Story-Telling Universe
}

\author{
Michael Lebowitz
}

January, 1984

To appear in Poetics 


\title{
Creating Characters in a Story-Telling Universe ${ }^{1}$
}

\author{
Michael Lebowitz \\ Department of Computer Science \\ Computer Science Building, Columbia University \\ New York, NY 10027
}

\section{Abstract}

Extended story generation, i.e., the creation of continuing serials, presents difficult and interesting problems for Artificial Intelligence. We present here the first phase of the development of a program, UNTVERSE, that will ultimately tell extended stories. In particular, after describing our overall model of story telling, we present a method for creating universes of characters appropriate for extended story generation. This method concentrates on the need to keep story-telling universes consistent and coherent. We also describe the information that must be maintained for characters and interpersonal relationships, and the use of stereotypical information about people to belp motivate trait values. The use of historical events for motivation is also described. Finally, we present an example of a character generated by UNIVERSE.

\section{Introduction}

One of the most interesting forms of story telling is extended story generation, the continuing serial. Such stories can take the form of short fiction, sequential movies such as Star Wars, The Empire Strikes Back, and Return of the Jedi, novel series, roleplaying games and, in one of its most popular forms, the television soap opera. The writer or writers of such serials face the prodigious task of creating and keeping track of literally dozens of intricately interrelated characters and numerous past and present plots. Extended stories of this type are likely the forerunners of the kinds of complex, interactive stories that will ultimately be created by programs when computers are used as more than simple word processors in the creation of fiction.

In this paper, we will describe the first phase of development of a story-telling

${ }^{1}$ Special thanks go to Susan Rachel Burstein who helped develop many of the ideas described here. Comments by Kathy McKeown and anonymous reviewers on an earlier draft of the paper were extremely helpful. Discussions with the writers of the television soap opera Days of our Lives were also quite influential. 
program, UNTVERSE. Ultimately, we hope to have UNIVERSE tell "soap opera" type stories entirely on its own. We include here an overview of the model of story telling we plan to use in UNIVERSE, based on the tracking of suthor goals. The majority of the paper deals with the creation of story-telling universes comprised of characters, their histories, family relations, and interpersonal relationships. Our ultimate goal in this research is both to better understand the cognitive processes human authors use in generating stories and to explore the practical prospects of computer programs that can engange in extended story generation for purposes of education or entertainment.

Extended story generation has all the hallmarks of an ideal topic for Artificial Intelligence research. Besides the obvious natural language processing issues, telling extended stories involves issues in knowledge representation (the information needed about people and events to tell interesting, believable stories), knowledge-state assessment (what the reader knows versus what the author knows versus what the various characters know), organization and access of information (keeping track of characters, their histories, and all sorts of ongoing plots), planning complex interactions among plots, author (or program) intent, and many other problems. ${ }^{2}$

As an illustration of the kind of stories we would like to generate, and the problems involved, consider the following synopsis of a small part of an episode of a daytime television show:

STORY1 - Seeing how unhappy Kayla is, Chris attempts to cheer her up. She explains that she's lost David to Renee. This news doesn't disturb Chris - now he can date Kayla! Later, while Chris and Kayla are in the park, David approaches and apologizes for hurting her. Renee told him that Kayla knows about their affair. He's loved Renee for a long time, David explains. After admitting she is hurt, Kayla promises to be his friend. David's both touched and guiltridden.

Because she's feeling depressed about her split with David, Kayla becomes

${ }^{2}$ In actual television soap operas, the problems are even grester, including the constraints imposed by actors' contracts and the need to achieve high ratings. 
drunk at Shenanigans [the local bar / restaurant]. Feeling guilty, David tries to tell her to stop, but she persists. When Chris walks into the club, be remarks how much he cares for Kayla and sends her home in a taxi. Therefore, he's surprised to find Kayls in his apartment when he returns bome! The landlady let her in, she explains. Drunk, Kayla falls asleep in Chris's bed. The next morning, she's embarrassed. Laughing, Chris assures her that nothing happened, even though he would have liked it to. ${ }^{3}$

STORY1 illustrates a number of problems faced in extended story generation. The main goal of the authors in this episode appears to be the ending of Kayla's romantic attachment to David on a friendly basis, and setting the stage for a new relationship with Chris. However, it is not possible to just state these changes, but rather they must be woven into a story. The story must be believable (in a sense we will describe later in this paper), and yet still not be totally predictable, since one goal of a story is to be entertaining. As a part of keeping the story believable, the characters must act in a manner consistent with their past behavior, an issue complicated by the extended nature of the generation process we are looking at. In extended story generation, we have to live for a long with every decision that we make.

To take examples from the excerpt above, notice how David does not simply dump Kayla, but makes a point of apologizing (as he is basically a nice person). Later, his behavior in trying to stop her from getting drunk is consistent with his earlier action, motivated by a guilty state of mind. Similarly, Kayla is basically a shy person, who would be unlikely to approach Chris romantically under normal circumstances, so her behavior is justified by having her get drunk. Notice that summarizing characters and mental states based on personality traits intuitively helps maintain consistency without having to analyze the connections between every pair of events a character is involved in. We will pursue the use of character traits later in this paper.

The events in a story, as well as the characters, must be kept consistent. So in STORY1, when Kayla is found in Chris's apartment, an explanation of how she got there must be provided. An extended generation program must do the same without producing enormous amounts of trivial event justification as a result.

${ }^{3}$ A description of part of an episode of Days of Our Lives, taken from Soap Opera Digest, October 12, 1982. 
It is also interesting how events at one point in time are used to prepare for further events. There are many characters who could have consoled Kayla, but since there were apparently further plans to have Kayla and Chris become involved, the authors took advantage of the David-Kayla breakup to initiate the Chris-Kayla relationship. It is this intricacy of events that both makes extended story generation complicated and allows the results to be entertaining over a long period of time.

It is important to recognize that stories such as STORY1 are not likely to arise by setting up a world and simulating probable events. In all likelihood a realistic simulation would not lead to such an interesting sequences of events, nor achieve the goals of the author. The injection of a random element to the simulation might make it superficially more interesting, but would not achieve any long-term consistency for its characters. So, while a strict simulation of STORY1 could reasonably lead to Chris "taking advantage" of the situation with Kayla, that would both be inconsistent with his basic character, and undermine a future relationship with her.

We believe that computer generation of stories at the level of complexity of STORY1 is a reasonable goal in the relatively near future. We bave currently implemented all the character creation algorithms described in this paper and outlined the generation process described in the next section. Expansion to include actual dialog generation, or perhaps interface with computer animation, may well take considerably more time. But even just by producing an outline of events in the manner of STORY1, we can create interesting stories.

\section{The UNTVERSE Model of Story Telling}

While we do not propose to give in this paper a complete description of the storytelling methods to be used in UNTVERSE, we provide a brief outline as a context for the character creation methods to be described in detail. It should also be emphasized that, unlike the character creation techniques, which have been fully implemented, the actual story-telling algorithms are still in development.

The major relevant Artificial Intelligence programs that our work is related to are Meehan's TALE-SPIN (Meehan, 1978) and Dehn's AUTHOR (Dehn, 1981). Both of these programs focus on the ability to tell planful narratives involving small numbers of 
characters, usually focusing on a single character. The work being discussed here has a rather different goal. We are not concerned with fully representing every last detail of every character and action, but rather with having enough information available to tell consistent, coherent, and hopefully interesting stories over long periods of time. An overall strategy for story telling somewhat similar to the one we will outline for UNIVERSE is presented by Yazdani (1883).

Research by psychologists into the process of writing has also influenced our work. Although little of this research has specifically addressed the generation of stories, analysis of other forms of language production suggest ideas that may apply to our task. Gregg and Steinberg (1980) presents a variety of recent work that suggests generation mechanisms that may be applicable to story telling. In particular, Flower and Hayes (1880) and Collins and Gentner (1880) suggest cognitive processes for generation based on the idea of constraints, that have been influential in the development of our storytelling methods. When applied to story telling, such methods will require the kind of characterizations that we discuss here.

While the amount of work done in the cognitive sciences on story generation is somewhat limited, a considerable amount of research has been done on story understanding, much of which can be applied to story telling. This work falls into two main groups - that which analyzes stories structurally and that which focuses on determining the conceptual content of stories, including relevant inferences.

The research into the structural form of stories is best represented by the development of "story grammars" begun by Rumelhart (1975) and pursued by Haberlandt (1980); Mandler and Johnson (1977); Stein and Glenn (1979); Thorndyke (1977). This body of work presents syntactic grammars for stories that include components such as episodes, settings, events and responses. While such grammars capture interesting information about the structure of stories, it is our belief that such structure is largely an epiphenominological result of the need for logical conceptual presentation of material, which is necessary in any case. Our research may ultimately lend insight to the need or lack of need for explicit structural analysis of stories by determining whether conceptual processing must lead to regularities such as those that story grammars describe. In particular, the need to keep stories believable will have 
structural effects, but imposing a structure during generation will not be adequate to achieve this believability. 4

The research into conceptual understanding of stories in both Artificial Intelligence and psychology has had more impact on our research. Much work has looked at the various knowledge structures needed for comprehension of stories, and methods for mapping text into these structures. Included in this body of research is work into general conceptual schema by de Beaugrande snd Miller (1880); Kintsch (1977); Kintsch (1980); Spiro (1980); causal chains by Schank (1975); scripts by Bower, et al. (1879); Cullingford (1978); frames by Charniak (1872, 1878); character plans and goals by Bruce and Newman (1978); Bruce (1980); Carbonell (1881); Wilensky (1983); themes by Schank and Abelson (1977); thematic affect units by Dyer (1982); and Memory Organization Points by Lebowitz (1983); Schank (1982). Any program that does story generation must produce the information needed for understanders to be able to extract information involving such knowledge structures. All of the structures in the research just mentioned may ultimately find their way into UNTVERSE. More research is needed to determine which structures must be represented explicitly for generation purposes, and which information should be stored in different forms.

Particularly important for generation, we believe, is work that analyzes stories in terms of high-level author goals. For example, Schank et al. (1982) and Wilensky (1880) look at the point that an suthor is trying to make with a story (or other utterance). The "points" that they extract from stories are likely to be at the core of the first stages of story telling.

Related research that we believe will be particularly important in our own work is that of Lehnert (1981) into plot units. She describes methods for analyzing and summarizing stories in terms of basic affective units - positive and negative events, and various causal and intentional relations among the events. Some of units formed by combining these basic units in standard ways, such as "hidden blessing" and "coerced double-cross" seem fundamental to the way stories are created. They can serve as a

\footnotetext{
${ }^{4}$ Black and Wilensky (1979) present difficulties with story grammars as a model of comprehension. Mandler and Johnson (1980) and Rumelhart (1980) reply to some of these difficulties.
} 
starting point in story generation, selected prior to determining concrete details. We will mention below the role plot units might play in UNIVERSE.

As informative as story understanding research is for our purposes, story telling does involve some unique problems. When understanding a story, we can assume that it makes some sort of sense, and base our analysis on that assumption. In generation, we are compelled to produce the logical connections that understanders will assume. Furthermore, while an understander can process text in whatever terms it has available, and ignore subtleties it is unprepared for, a good story telling program must produce stories that can be analyzed at any level at which an understander might operate.

Story telling in UNTVERSE is a plan-based activity. In this sense it is related to work that has been done on low-level text generation, including Appelt (1882); McDonald (1880); McDonald and Conklin (1882); McGuire (1880); McKeown (1882), but operating at a much more conceptual level (although eventually we will, of course, also need to generate text). An entire UNIVERSE story cannot be planned out, since the kinds of stories we envision theoretically do not end. Instead, once a body of events has been planned, that portion of the story is told. Story telling becomes the expansion of goals, in the problem-solving sense, until they lead to actual events that can be generated.

The goals that UNIVERSE deals with fall into two classes - character goals and author-goals. Character goals must be monitored to maintain consistency. This process is similar to the way TALE-SPIN simulated its story world (Meehan, 1978). However, as discussed by Dehn (1981) and others, in order to create interesting and meaningful stories, it is necessary to pay attention to the goals of the author. In fact, the expansion of author goals controls UNTVERSE's story-telling algorithm, with character goals providing secondary constraints on what the characters are allowed to do. The author goals may involve various levels of detail, but most important will be goals that call for the instantiation of high-level structures, such as Lehnert's plots units, for specified characters. For example, an author goal might be to cause the occurrence of Mary "double crossing" John (which may incidentally involve other characters).

In order to tell stories, UNTVERSE maintains two precedence graphs that illustrate how the various pending author and character goals relate to each other and to events 
that have been told already. Then, the program selects an author goal to expand, and continues this process recursively, until enough goals reach "ground level", i.e., actual events, at which point the events would be told to the reader using natural language generation methods. Note that the story-telling process can both make use of alreadyexisting characters, or cause new characters to be created. The author goals typically do not form a single hierarchy, and can include very long-term goals that lead to "dropping hints" to motivate events that may occur much later.

To illustrate how the story-telling process might go, consider the following example. Imagine that the program (or human author) has decided that John and Mary should fall in love (to satisfy higher level suthor goals - for instance, perhaps Mary's husband, presumed dead, is about to return, which should produce interesting results; notice that it is not necessary to plan out to the bitter end what these results will be to expect them to be interesting). One author plan for having characters fall in love is for them to lirst be friends, and then to have something terrible happen to one character, so that the other can provide consolation that can believably turn into love. If John and Mary are already known to be friends (and the reader knows this), then UNTVERSE can set a goal for something terrible to happen to one character, and recursively pursue that goal until a tellable event is decided on, say one character's child is kidnapped, at which point some story generation can begin.

For the process we have described in this section to take place, it is necessary to have richly specified and believable characters. In the remainder of this paper, we will describe how such characters can be generated.

\section{Motivating Character Creation - Consistency and Coherence}

Good extended story telling is constrained by the need to maintain consistency and coherence. A story is consistent if properties and events of the story world (including properties of characters) do not include any explicit or apparent internal contradictions. For example, a 34-year-old man should not become 47 overnight, nor should bitter enemies become close friends without explanation.

Coherence involves the idea that events should logically explainable, at least in 
retrospect, from the information available to the resder. Thus a reader should be able to build up a causal representation of the events in story, as in Schank (1975), as they take place. While it is neither necessary nor desirable to provide the reader with enough information to actively predict every event that will occur in a story, events should make sense when then do occur. Most notably, actions should be based on the personalities and backgrounds of the characters involved. Thus, it would be inappropriate for a mildmannered school teacher to hire a hit-man to deal with a school board that fired him.

Surprises are fine. But unjustified surprises tend to be very dissatisfying to readers (or viewers). UNTVERSE creates a universe of characters before beginning to tell a story in order to maintain consistency and coherence. It would certainly be possible to create characters only when required during plot generation and fill in details of these characters only when needed. Sometimes UNTVERSE will do just that. However, in order to keep the qualities of characters consistent, and to be able to insert information into the story that will lead to later coherence (i.e., "drop hints"), it is useful to have a substantial set of characters in place when story telling begins. In addition, most stories that are generated will be based on the already existing characters, since the arbitrary creation of new characters undermines coherence, so initializing the universe avoids "start-up" problems.

Another way of looking at the issue of coherence is that we would like aspects of our story-telling universe to be motivated. We are not simply concerned about predicting a character's behavior given a description of him or her (although that too will be an issue), but rather, given an action that we, as the author, would like a character to do, how to we motivate this action, i.e., make it seem reasonable to the reader. In our model, such motivation may take the form of character traits (e.g., the character is mean), interpersonal relationships (e.g., the character hates his siblings), events in the character's past (e.g., the death of the character's spouse), all of which must in turn be motivated.

Coherence provides benefits beyond merely protecting the reader from untoward surprises. In large part, coherence provides the "flavor" that, while hard to define precisely, makes serials so popular. It is difficult for a reader to identify with characters whose actions seem inconsistent. Part of the enjoyment of soap operas is speculating 
about what will happen next, a game that is fun only if plot actions are coherent. For similar reasons, characters should also have some history. Knowing a bit about their past allows for coherence, and is another potential source of navor.

\section{Person Frames}

To maintain consistency in stories, we must consider the information to be created and maintained about people. ${ }^{5}$ This collection of information will be referred to as a person frame. Previous work in this area, particularly that of Carbonell (1881) and Schank and Lebowitz (1979), was concerned with complex plan-and-goal-based representations that allowed an understander to explain a person's actions. We will use here a somewhat simpler representation that provides enough information to generate believable story plots, by concentrating on personality traits, interpersonal relationships and, to some extent, goals. We must also maintain information to motivate these traits and goals. We will focus on ways to make character information consistent and coherent.

The coherence issue is an important one here. No matter what information we maintain about characters, it is important that it be motivated. While we could just make up personality traits and goals for each character, that would not be satisfying to a reader.

Ways to provide the needed motivation and coherence can be seen by considering how we might answer a question such as, "Why is Aaron so cold-hearted?" Two possible answers are, "He's a door-to-door salesman" or "He got that way after his wife left him". These answers are illustrative of two ways to make character descriptions coherent, stereotypes and past events.

Stereotypes are common descriptions associated with people in various classes such as occupations, social groups or personal backgrounds. A stereotype conveys a large amount of "default" information, and tends to provide enough coherence to satisfactorily motivate an aspect of a character's make-up. So, for example, if we know that a person

\footnotetext{
${ }^{5}$ What makes a character interesting is a complicated subject itself. In this paper we will rely on an idea of interest that a character is interesting if somewhat unusual, but still believable, as discussed by Lebowitz (1981). More on interest can be found in Schank (1978).
} 
is a doctor, it is reasonable to assume that he or she is intelligent, well-educated, and probably well-off financially, unless we are told otherwise. Further, the fact that the person is a doctor provides an acceptable motivation for any of these characteristics. A cognitive psychological analysis of the use of character stereotypes in writing appears in Adams and Bruce (1980). Note that facets of stereotypes can always be overridden, although if too many facets are overridden, then the particular application of the stereotype must be considered questionable.

Stereotypes, therefore, comprise an important part of character descriptions. The description of a character in UNIVERSE contains a list of one or more stereotypes from which the character inherits properties, unless overridden. Besides providing coherence, this form of representation also allows for economy of storage, as we do not have to repeat information from a stereotype for each character that fits it. The stereotypes used here serve much the same role for person descriptions as generalization-based Memory Organization Points (Schank, 1982; Lebowitz, 1983b) (stereotypical events built up from specific instances), do for events. In each case, large amounts of information are stored with stereotypes and only the unique properties of specific items, characters or events, are stored explicitly. The contents of stereotypes will be examined shortly.

Past events are used primarily to provide variety and motivate aspects of a character that do not fit stereotypes (though it is possible to create a wide variety of characters just by combining stereotypes). By including historical events in a storytelling universe, it is possible to have interesting variations in the various characters, along with adequate justification to assure coherence. (To achieve the coherence, it is, of course, necessary to refer to the various past events so that the reader is aware of them.) In the complete version of UNTVERSE, as the program tells stories it will naturally update the history of the characters involved.

The final important class of information needed about the characters involves not individual characters, but interpersonal relationships among characters. Crucial to the selection of consistent plots is the need to monitor the way characters relate to each other. If two characters are best friends, we would not expect one to have an affair with the other's spouse. If such an event did occur, and the other friend became aware of it, we would expect the interpersonal relationship to change. To achieve consistency of this 
sort, we must maintain information about relationships potentially between every pair of characters in our universe. Many interpersonal relationships will be created and modified when historical events are added to the particular universe. The creation of interpersonal relationships often provides motivation for authors to include historical events.

One class of interpersonal relationships that is important enough to require special handling is family relations - husband/wife and parent/child. As will be shown when the creation of story-telling universes is presented below, past and current marriages and the offspring that result can provide the motivation for many of the characters and interpersonal relationships in a story-telling universe (particularly for soap operas). For each character, we maintain a list of the marriages, including offspring. For more complete coverage, we will probably extend this in the future to other long-term, marriage-like relationships (such as affairs and couples "going together" or living together).

Figure 1 summarizes the information stored in a person frame. Traits and goals will be discussed further in the next section, when stereotypes are presented. The values stored in individual person frames are used to override values inherited from stereotypes. One component in Figure 1 not described so far is the character's name. The only interesting point about names is that in most extended stories, character names behave just like good computer programming variables - neither first or last names are ever duplicated (with the exception of members of the same family, of course).

\author{
Name \\ Stereotypes \\ Individual traits \\ Individual goals \\ Interpersonal relstionships \\ Marriages \\ History (list of events)
}

Figure 1: Person frame information 


\subsection{Stereotypical frames}

UNIVERSE stereotypes provide two basic types of information about the characters they describe - descriptors of physical and personality traits, and typical goals. Personality traits are particularly useful in selecting characters for a given plot (or selecting plots for a character to be involved in). For example, in a blackmail plot, the blackmailer should not be a nice person, and the person blackmailed, or his family, should have something worth extorting.

Goals tend to be important in a somewhat different context. When UNTVERSE expands author goals, it makes use of plot schemas, similar to Lehnert's plot units mentioned earlier, that are abstract in terms of the events they describe. "Revenge" would be an example. To "execute" such plots, it is often necessary to have information about various characters' goals - particularly long-term goals - in order to understand what is important to them. The many uses of goals in language generation and understanding are discussed extensively by Allen (1979); Appelt (1982); Carbonell (1981); Cohen and Perrault (1979); Meehan (1976) Schank and Abelson (1977); Wilensky (1983) and others.

The selection of traits to be used in stereotypes is certainly not self-evident. We need a set of traits wide enough to indicate which characters should participate in which plots and how they should fare in such plots. If no character's behavior depends on a given trait, it is pointless to include that trait in descriptions. The traits chosen for UNIVERSE, along with the values they can take on, are shown in Figure 2. No claim is made that this listing is exhaustive. However, it allows for a wide range of behaviors to be explained, and can be easily extended.

As shown in Figure 2, many of the traits possessed by characters in UNTVERSE are assigned numeric values within arbitrarily defined ranges. -10 to 10 ranges were used for traits normally thought of as having positive and negative aspects (e.g., niceness, where a character can be either "nice", "mean" or neutral) and 0 to 10 ranges for traits that indicate the presence or absence of some property (e.g., intelligence, where the low values indicate lack of intelligence, not some sort of negative intelligence). While this undoubtedly does not capture all people know about these traits, it seems adequate for 


\section{TRAIT}

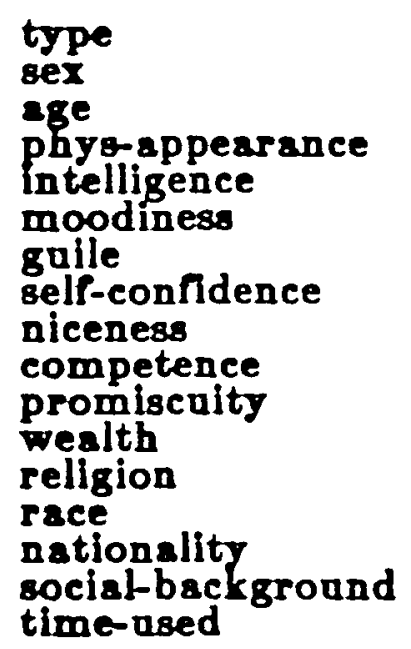

POSSIBLE VALUES

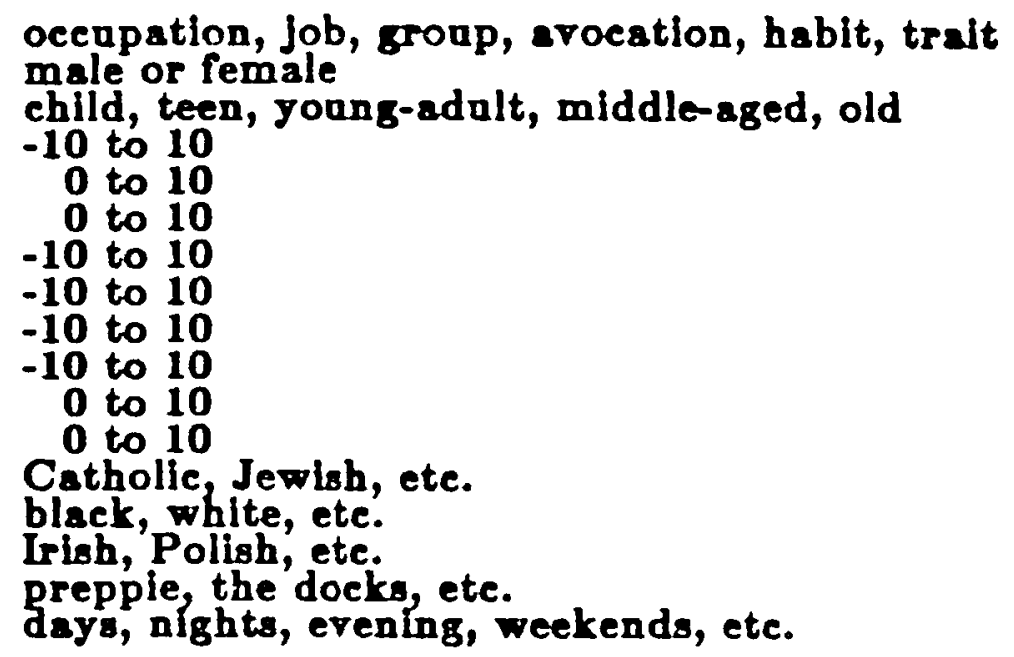

Figure 2: Person stereotype traits

determining who can plausibly do what. Fine differences in numeric values are rarely significant. Generally only gross differences in values, or comparative values are important.

Figure 3 lists the trait values for several stereotypes used in UNIVERSE. (Note that these stereotypes reflect the author's view of how such characters are portrayed in popular literature, which may not bear strong connection to the real world!) Where a stereotype has no value for a given trait, it does not contribute to our knowledge of that trait for any character described by that stereotype.

We will not discuss goals in detail here, since, as mentioned above, they are welldescribed elsewhere in the literature. Suffice it to say that we are concerned primarily here with characters' long-term goals, such as the achievement and preservation goals of Schank and Ableson (1877), rather than short-term, planning-type goals (although those will be important in actual story telling). Examples of the kinds of goals dealt with in stereotypes are that doctors want to make money and establish lucrative practices, professional athletes want to become famous, and everyone is trying to find happiness.

Figure 4 shows a selection of the over 50 stereotypes included in UNIVERSE. (Many more could easily be added.) It is possible to motivate quite a variety of characters simply through stereotypes. 
type

intelligence

phys-appearance

moodiness

gulle

self-conndence

niceness

competence

promisevity

sex

age

wealth

religion

race

nationality

social-background

time-used

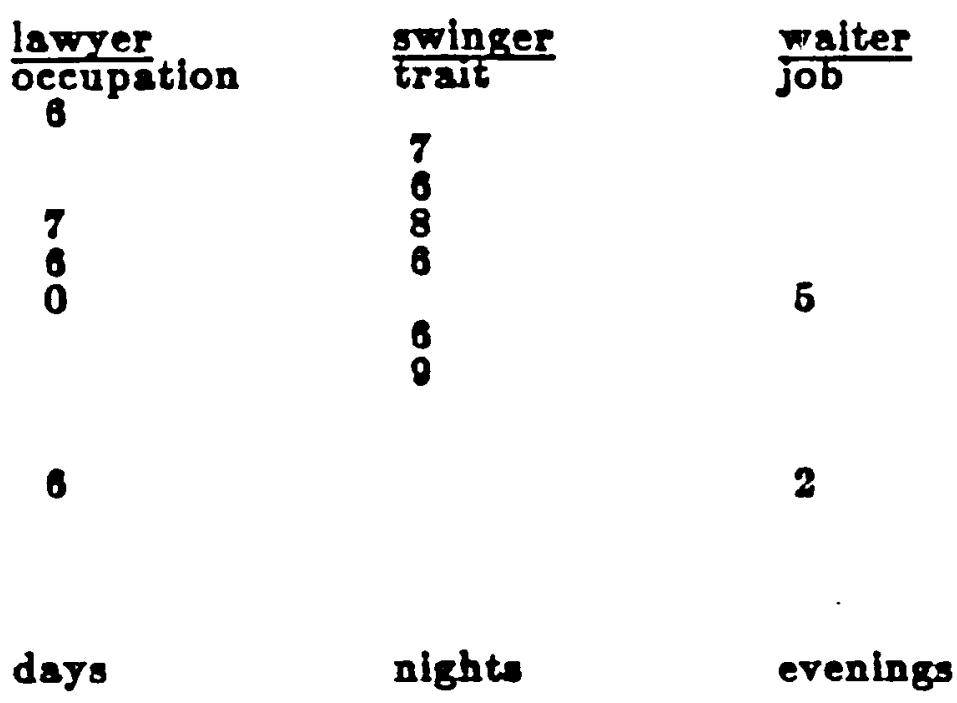

Figure 3: Sample stereotype frames

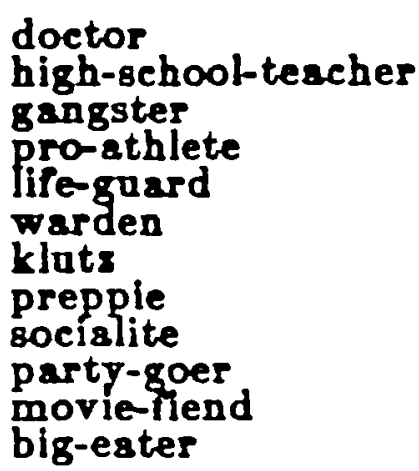

doetor

high-school-teacher

gangster

pro-athlete

life-guard

warden

prepple

party-goer

big-ester

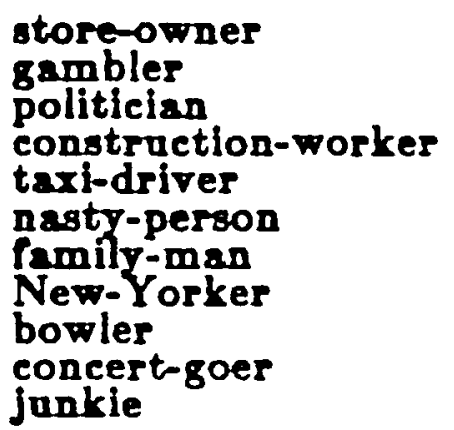

store-owner

gamble?

actor

bureanerat

receptionist

truck-driver

nake

owinger

nirt

hari-krishna

video-game-player

sports-fan

drunk

Figure 4: Some of the stereotypes used in UNIVERSE

\subsection{Creating characters to specincation}

The process of story-telling universe creation, and story telling in general, often requires the creation of characters with specified traits (to explain participation in a past or current plot, or as the child of other characters, perhaps), not necessarily characters with given stereotypes. Thus, a procedure to find a set of stereotypes that reasonably describes a character, given a set of trait values, is required.

Even though it is difficult to come up with sn optimal set of stereotypes, it is not 
hard, using heuristic methods, to come up with a reasonable set. UNIVERSE does this by first selecting an occupation for the character that has the minimal total discrepancy from the traits specified. Then, for each trait specified but not yet perfectly described, snother stereotype is picked that does not alter existing values, but brings the person closer to the desired value for the trait. This process tends to leave only minor variations to be accounted for by personal idiosyncrasy.

This "create to specification" algorithm yields interesting, but believable combinations of stereotypes such as teacher/swinger (ala Looking for Mr. Goodbar) or warden/video-game-player/movie-freak.

\subsection{Interpersonsl relationships}

While it is important to have individual characters adequately represented, it is also necessary to represent interpersonal relationships between characters. We have chosen to do this with a set of numeric scales, based on those from the psychological experiments of Wish et al. (1976), extended for Artificial Intelligence use by Schank and Abelson (1977). This work posited three scales - positive/negative, intimate/distant and dominant/submissive - to describe the way people relate to each other. To these we have added a fourth scale, attractedness, appropriate for soap opera universes.

The four scales used to represent interpersonal relationships in UNTVERSE undoubtedly do not describe all that can be known about how two people interrelate, but as with the traits selected to describe UNIVERSE characters, these scales are adequate for most story generation purposes. Deutsch (1982) suggests a broader set of scales that may be used in later versions of UNTVERSE.

One important way in which our use of scales differs from the description of Schank and Ableson (1977), is that we allow there to be two sets of values for each relationship to reflect each character's perception of the relationship. There is no obvious reason to assume that interpersonal-relationship scale values are reflexive. Each character's actions should be based on their perception of the relationship, not some absolute value. In fact, it would be possible to make a case for an even more complicated system, where there is information about characters' perceptions of other characters' perceptions (i.e., I think he thinks I like him, even though I really don't). Allen (1981) 
and Clark and Marshall (1981), provide many examples showing where such information is needed. However, for the most part, the scheme used in UNIVERSE allows events to be generated coherently, and in any case, the embedding would have to be restricted to a reasonable level.

As with individual character information, values of scales can come either from stereotypes or past events. In stories, past events seem to be more important in shaping interpersonal dynamics. While there are a reasonable quantity of stereotypical relationships - among family members and people in occupations, for example - events such as shared crises, conflicts at work, marital conflicts, and the like, tend to be more significant in explaining coherently how one person relates to another. This is an important reason why story-telling universes incorporate a history of events.

Stereotypical relationships include values for each character's perception of any of the scales used to describe interpersonal relationships. They may, optionally, also include person stereotypes that describe either or both of the characters in the relationship. Figure 5 illustrates a typical stereotypical relationship, that between a doctor and patient. There are no stereotypes for the patient, as any character can play this part in a doctor-patient interpersonal relationship. Each scale runs from -10 to 10, with greater values indicating stronger positive feelings, intimacy, dominance, or physical attraction.

doctor-patient

possible doctor stereotypes: doctor psychologist possible patient stereotypes: <none>

scale pos-nes int-dis dom-sub attract

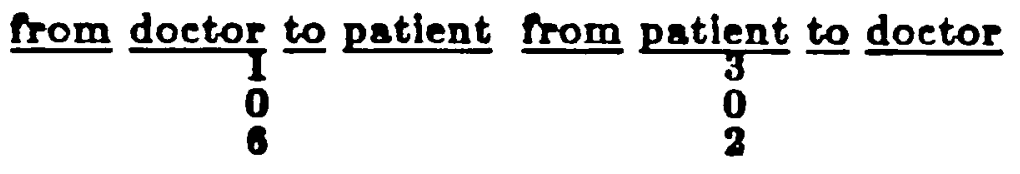

Figare 5: Doctor-patient stereotypical interpersonal relationship

Figure 6 illustrates a typical interpersonal relationship of the sort we would like to build up. It describes a relationship between two people, John Smith and Mary Jones, his ex-wife. (As always in this paper, the specific numbers should be taken with a grain 
of salt.) The relationship is described by a stereotypical relationship that exists between ex-spouses. This stereotypical relationship is modified as shown (John is still strongly attracted to Mary, who, unfortunately for John, hates him). The values in parentheses come from the stereotypical relationship. We would expect this relationship to lead to plots involving John's attempts, presumably unsuccessful ones, to regain Mary's affections.

person 1 : John Smith person2 : Mary Jones Interpersonal-relation stereotypes: ex-spouse

seale pos-neg int-dis dom-sub attract from personl to person2 from person2 to person 1

(1)

Figare 6: A sample interpersonal relationship

\section{Building Up a Story-Telling Universe}

Having specified the kind of information we would like to maintain about the characters in a story-telling universe, we are still left with the problem of how to generate that information. Certainly we could assign values to characters randomly, or arbitrarily assign traits and create characters to specification. We could specify properties for characters and interpersonal relationships only when needed for a plot (a necessary mechanism in any case). These plans (ail to provide adequate coherence to the story universe.

To see how to add coherence to our set of characters, consider the universe of characters in a typical television soap opera, Days of Our Lives. Figure 7 lists most of the active characters in this NBC soap opera at a given point in time.

The first thing we see from Figure 7 is that the relationships among the characters are quite complex (an informal count showed at least 205 identifiable interpersonal relationships), and that many of the characters are related to each other by past and present marriages of one sort or another. Husband-wife and parent-child relationships 
Tom and Alice - Horton family patriarehs

Mickey and Maggie - son and wife

Sarah - their daughter (by artineial insemination)

Meliesa - child under guardianship of Mickey and Magsie

Julie and Doug - granddaughter and husband

David - Julles son

Trish - David's ex-wife

Seotty - their son

Marie - another Horton daughter (ex-nun)

Alex - her ex-husband

Jessica and Joshua - granddaughter and nance

Stephano - the bad guy

Tony - his son

Renee - Tony's half-sister (a recently discovered relationship)

Lis - Tony's estranged wife

Don - Lis's ex-husband (sort of, she was actually still married to Tony then, it gets complicated)

Marlens - another of Don's ex-wives

Johnny - her foster son

Roman - Marlens's nance

Kayla - his sister

Anna - Roman's nist wife, presumed dead in an accident

Figure 7: A sample soap opera universe

add coherence to the character set in most soap operas. In addition the relationships change quickly. For example, Roman's wife, Anna, presumed dead, showed up with their daughter a week after Figure 7 was made. (Notice, how the lact that Anna was only presumed dead allowed her to return consistently.)

We would like to have this same sort of coherent intricacy among the characters created by UNIVERSE. The most feasible way to achieve this is to, in effect, do a simple simulation of the past lives of characters, creating spouses, children and other assorted characters as necessary. We thus view marriages as a motivation for creating characters rather than as arbitrary relationships that should be established after we have created a set of characters.

The simulation used by UNIVERSE involves cyclical character creation. A queue is maintained of characters who have been created during the simulation, but have not had the details of their lives filled in. Each character is, in turn, removed from the queue, and UNTVERSE steps through his or her life, creating spouses and children. When the present is reached, further details of the character, such as occupation and other descriptive stereotypes are filled in. 
The selection of the specific events that occur can be done somewhat arbitrarily, perhaps constrained by various character traits, if we are developing background for a character created to satisfy a specific author goal during story telling. Arbitrary selection is not as unreasonable as it may sound, as the idea is to have interconnections among characters, although relevant author goals should be considered, if present. Often the details are not too important, as long as the events that occur are reasonable (e.g., no one is married and divorced 82 times).

The simulation of characters' lives can be separated into two phases - when they are married and when they are not. The kinds of events that can occur in these two states, at least the events we are concerned with here, are sufficiently different that it simplifies matters to treat them separately. UNIVERSE breaks the simulation of characters' pasts into "life cycles" and "marriage cycles".

Figure 8 shows the basic "life cycle" character simulation. The heart of the process shown in Figure 8 is the loop that steps through the years of a character's life, checking for "life-changing" events. For an "unattached" person, the events currently handled by UNIVERSE are death and marriage. In the case of a marriage, UNTVERSE switches over to the "marriage cycle". Other possible appropriate events, including affairs and assorted romantic relationships, can easily be added within this framework.

Figure 9 shows the processing that occurs to simulate, in broad, terms a marriage between two characters. The marriage cycle operates in much the same way as the life cycle. The marriage is stepped through, determining whether any marriage-related events, including having children, getting divorced, or either spouse dying, have occurred.

An important feature of the marriage cycle occurs when it begins. The first thing to be done is to select a spouse for the person getting married. By allowing both the possibility of selecting as a spouse an already existing eligible character (where eligible is defined as someone who is single, of appropriate age and sex, and not directly related to the person in question) or of creating a new person with appropriate characteristics, we create many interesting interrelationships among the characters. We are able to have a 


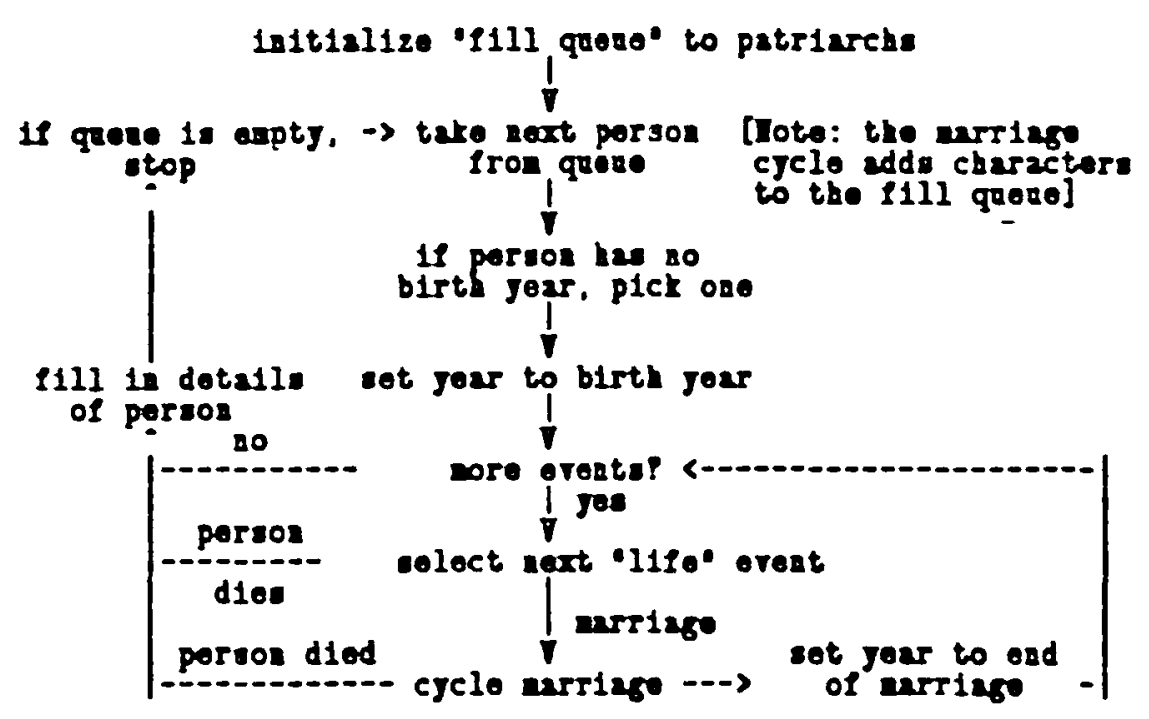

Figure 8: UNTVERSE character "life cycle"

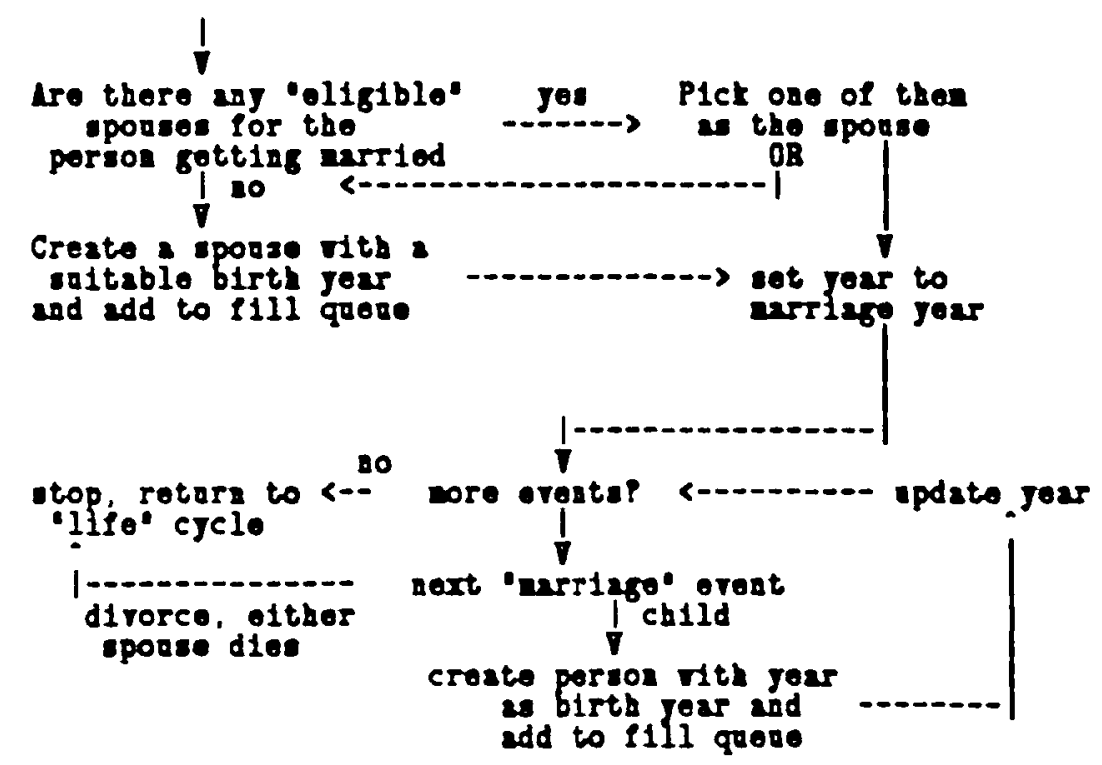

FIgure 0: UNIVERSE "marriage" cycle

complex web of past and present marriages, along with the associated children, while maintaining consistency.

Once the major events in the character's life have been determined, additional details about the characters, including appropriate stereotypes, are filled in. The 
algorithm described in Section 4.2, begins with a set of traits values for each new character and select stereotypes that motivate them. In the normal story-telling process, these initial traits will arise from primarily from author goals. The current version of UNTVERSE selects several personality traits from the person's parents (if known in the simulation), to be inherited, which adds coherence in the form of parent-child similarity. Other trait values arise from the stereotypes that are selected by the character description algorithm.

\section{Adding More Background}

Although the cyclic character creation process described in the previous section provides the framework for the story-telling universes created by UNIVERSE, it is not quite enough by itself. There are three main problems with the universes created: 1) Almost all the characters are related in one way or another; 2) Almost all the interpersonal relationships in the universe have to do with marriages and children; 3 ) There is no history, other than marriages and offspring, to the characters, a detriment to coherence.

Fortunately, we can solve all three of these problems with a single mechanism, one related to the main thrust of the UNIVERSE program. The answer is to simply add history to the characters' backgrounds by "executing" in the past, simplified versions of the plots UNTVERSE will create for the present.

It is crucial to note that the past plots run by UNTVERSE need not be executed in the same detail as during actual story telling. Instead, it is enough to merely determine how each plot affects the characters involved and the relationships among them, and modify their histories appropriately. UNTVERSE can then add coherence to its current stories by referring to events in the past. In addition, the mechanism for selecting the plots to be run need not be the same as for real story telling. Instead, we can select a given plot in order to obtain a desired interpersonal relationship, without requiring the same level of motivation as is needed in actual generation. The author goals behind the selection of historical plots can be broader than those used for detailed story telling. We will focus here on the information needed about historical plots, and the advantages gained by having them. 
"Executing" historical plots solves all the problems mentioned above. The plots will sometimes call for the creation of new characters, providing a source of unrelated characters, without ruining the framework of the universe. Furthermore, such plots will provide interesting and novel, yet coherent, interpersonal relationships (e.g., Mary dislikes Hank because he threw the big basketball game in high school). Finally, almost by definition, these plots add historical navor to the characters in the story-telling universe.

Figure 10 shows the information that is needed for a plot to be executed historically. This same information will be useful, although it will have to be augmented, in actual story telling. The most relevant information in Figure 10 is the description of how character traits and interpersonal-relationship scale values should be modified for each character. It is this information that will allow a novel, but coherent, universe to be built up. Also significant are the constraints on the characters (which will usually involve individual character traits or interpersonal relationships) that force consistency upon past events.

\section{plot name \\ time frame [e.g., days, months, years] \\ role list [including prototypes specined for each role] constraints on role nllers how character traits should be modified how interpersonal relationships should be modified}

Figure 10: Plot components

Figure 11 shows some of the plots that can be run historically by UNTVERSE. The variety here allows a multitude of interesting story-telling universes to be built up.

The execution of sufficient historical plots adds coherence to story-telling universes as many of the characters end up with interpersonal relationships between them, with coherent motivations for the relationships. 


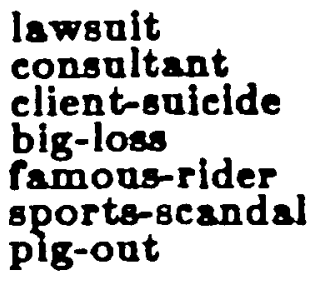

lawsuit consultant client-suielde big-loss famous-rider plorts-ont

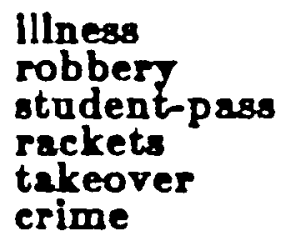

malpractice competition cutback bribe attempted-suicide diet

Figure 11: Sample historical plots

\section{A Sample UNIVERSE Character}

As an illustration of the end product of UNIVERSE's character creation process, Figure 12 shows a typical character created. The character "Jessica Donadio" was created as part of a typical UNIVERSE story-telling universe. The motivation for creating the character arose when the life of "Douglas Davidson" was cycled, and a decision made that he should be married. In the cycle of their marriage, they had two children and were subsequently divorced. Jessica later bad a second marriage (created when her life was cycled), which also ended in divorce.

In the full-blown UNTVERSE story generation system, we can imagine a number of other situations that might motivate the creation of this character. For example, suppose UNTVERSE had generated STORY1, shown earlier and was now continuing that story. One of the main plots to be extended is Chris and Kayla's impending romance. One author goal might be to put obstacles in the way, since, from the author's point of view, "happily ever after" is not too interesting. (Notice that there is no reason this would necessarily happen if we just simulated the world by pursuing the characters' goals.) The instantiation of this author plan might be to introduce a plausible alternative character with which Chris could pursue his romantic goals.

This scenario would require another female character. However, if the ultimate author goal is for Chris and Kayla to end up together, then we must prepare a reason for Chris to eventually reject this other character. One possibility would be for this woman to be devious and promiscuous, which would justify an initial seduction of Chris, but also justify him returning to Kayla when he discovers her true nature. If a character with these "qualifications" does not exist, or the use of an existing character would have 


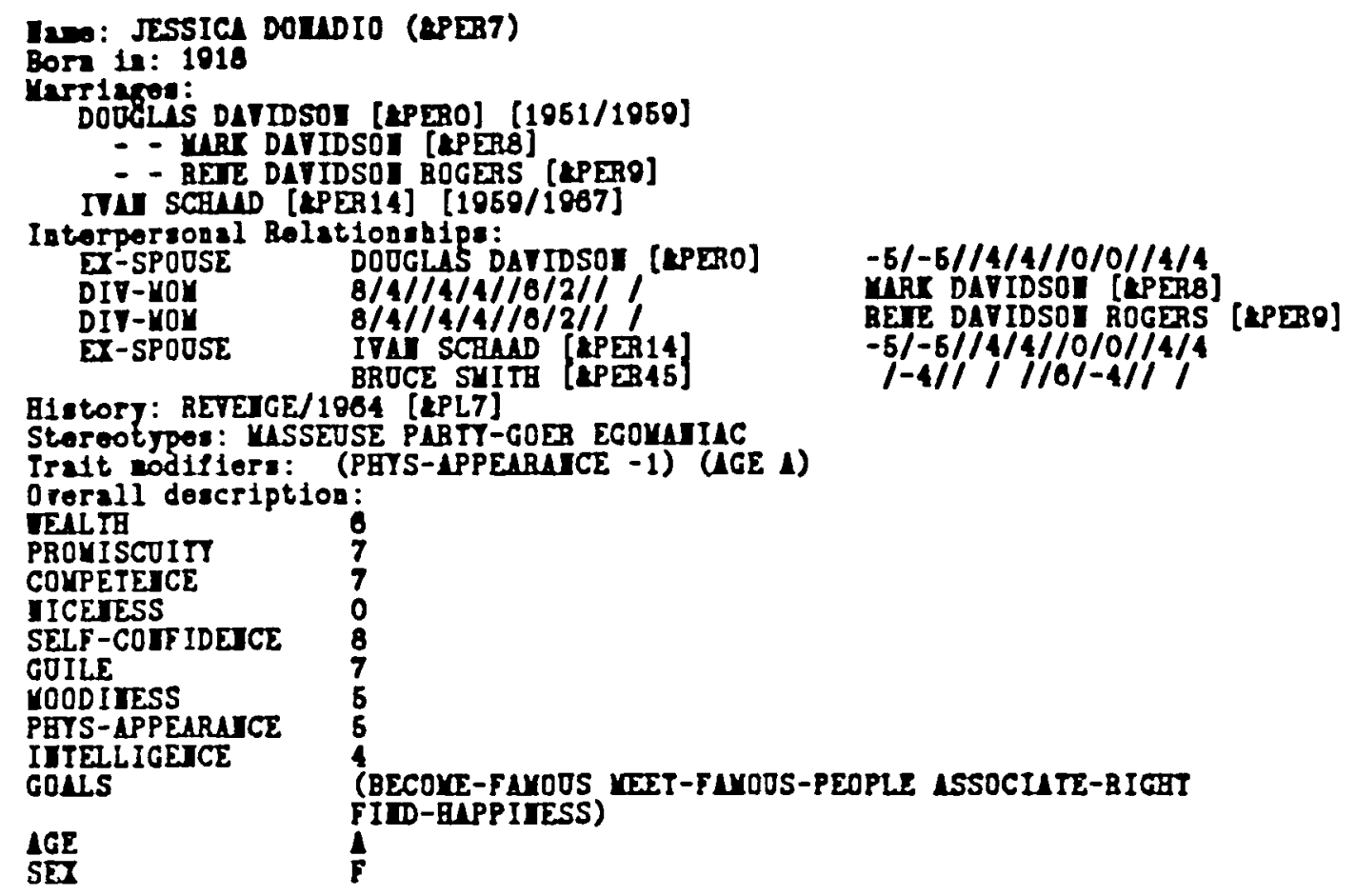

Figure 12: A Sample UNIVERSE Character

undesired side-effects, then we would have to create a new character with the specified characteristics, such as "Jessica Donadio".

For reasons of coherence described at length in this paper, it is not acceptable to just give Jessica the characteristics we want, and no others. Instead, we use stereotypes to motivate the required characteristics. For example, the "masseuse" and "party goer" stereotypes shown in Figure 12 both have positive positive promiscuity values that help motivate that trait. Similarly, the "egomaniac" stereotype coherently explains the desired deviousness (high "guile" value). The remsining traits in Figure 12 are sideeffects of the stereotypes selected. UNTVERSE is forced to consider all the implications of its stereotype selection, such as the relatively high "physical appearance" trait value, which comes from the "masseuse" stereotype. The character's behavior must be consistent with this and other trait values not explicitly specified, as well as those that were originally desired.

Thus, while the stereotypes shown in Figure 12 were actually selected in order to explain several character traits that were selected somewhat arbitrarily in the computer 
run of the current version of UNIVERSE, the same process regularly occurs during story telling to enhance coherence.

Further coherence and consistency issues might bave arisen in the specification of the Jessica character. Had she been created as the offspring of other characters, there would have been additional constraints placed on her stereotypes, in order to maintain consistency (of race and national background, for example), and several character traits might have been assumed inherited. While no constraints were specified in the current system for Jessica based on the need for her to be an appropriate spouse for Douglas Davidson, this would be a logical addition to the model presented here.

Jessica's marriages and offspring account for most of her interpersonal relationships (although they, too, could be the result of story-telling constraints). She has stereotypical "ex-spouse" relationships with her two ex-husbands, Douglas Davidson and Ivan Schaad, as well as stereotypical "divorced mother" relationships with her two children. These stereotypical interpersonal relationships are the source of the interpersonal scale values shown in Figure 12. For each relationship there are up to four pairs of numbers shown, representing the four scales described in Section 4.3. So, for example, the relation between Jessica and Douglas on the positive/negative scale has the -5 value (e.g., negative feelings) specified in the ex-spouse stereotype, along with other values specified by that stereotype. As with trait values, it is necessary to accept these values, which are side effects of their divorce, and have the characters act accordingly, or introduce an event or another stereotypical relationship to motivate a different value.

Jessica has one additional interpersonal relationship, with "Bruce Smith". It arose from a past event, "revenge" as it happens. This event produced values for several of the interpersonal relationship scales. We know that Jessica has negative feeling about Bruce, but he is in a position of power over her. These values cannot be described by any stereotypical relationships (although that sometimes happens with event-generated relationships), so the raw scale values are listed. If these characters are further developed in story telling, their actions towards each other will be governed by the values that arose from the "revenge" event, unless modified by further events or new stereotypical relationships where they interacted (their children married, for example). 


\section{Conclusion}

We have presented here a method for generating extended story-telling universes, consisting of characters, interpersonal relationships and historical events. The method of creating characters focuses on maintaining consistency and coherence. The methods described are nexible enough that they can be extended to address additional problems, such as specific author intent, by adding constraints in the character generation process. The work described here provides the framework for the extension of UNIVERSE to actual story telling, using an author-goal-based generation scheme.

The study of extended story generation provides exciting opportunities for both understanding human cognitive processes and participation in the development of education and entertainment forms of the future. 


\section{REFERENCES}

Adams, M. and Bruce, B., 1880. Background knowledge and reading comprehension. Technical Report Reading Education Report Number 13, Center for the Study of Reading, Champaign, $\amalg$.

Allen, J. F., 1978. A plan-based approach to speech act recognition. Ph.D. Thesis, University of Toronto, Computer Science Department.

Appelt, D. E., 1982. Planning natural language utterances. Proceedings of the Second National Conference on Artificial Intelligence, Pittsburgh, PA, pp. 58 - 62.

Black, J. B. and Wilensky, R., 1878. "An evaluation of story grammars." Cognitive Science 3:213 - 228.

Bower, G. H., Black, J. B., and Turner, T.J., 1979. "Scripts in text comprehension and memory." Cognitive Psychology 11:177 - 220.

Bruce, B., 1980. "Analysis of plans as a guide to the understanding of story structure." Poetics 8:285 - 312 .

Bruce, B. and Newman, D., 1878. "Interacting plans." Cognitive Science 2:195 - 233.

Carbonell, J. G. Jr., 1881. Subjective Understanding: Computer Models of Belief Systems. UMI Researcb Press, Ann Arbor, Michigan.

Charniak, E., 1972. Understanding children's stories. Ph.D. Thesis, MIT.

Charniak, E., 1978. On the use of framed knowledge in language comprehension. Technical Report 137, Yale University Department of Computer Science.

Clark, H. H. and Marshall, C. R., 1981. Definite reference and mutual knowledge. In A. K. Joshi, B. L. Webber and I. A. Sag, Ed., Elements of Discourse Processing, Cambridge University Press, New York .

Cohen, P. R. and Perrault, C. R., 1979. "Elements of a plan-based theory of speech acts." Cognitive Science 3:177 - 212.

Collins, A. and Gentner, D., 1980. A framework for a cognitive theory of writing. In L. Gregg and E. R. Steinberg, Ed., Cognitive Processes in Writing, Lawrence Erlbaum Associates, Hillsdale, New Jersey, pps. $51-72$. 
Cullingford, R., 1878. Script application: Computer understanding of newspaper stories. Technical Report 116, Yale University Department of Computer Science.

de Beaugrande, R. and Miller, G. W., 1980. "Processing models for children's story comprehension." Poetics 8:181 - 202.

Dehn, N., 1881. Memory in story invention. Proceedings of the Third Annual Conference of the Cognitive Science Society, Berkeley, California, pp. 213 - 215.

Deutsch, M., 1882. Types of interdependence and psychological orientations. Teachers College, Columbia University.

Dyer, M. G., 1882. In-depth understanding: A computer model of integrated processing for narrative comprehension. Technical Report 218, Yale University Department of Computer Science.

Flower, L. S. and Hayes, J. R., 1880. The dynamics of composing: Making plans and juggling constraints. In L. Gregg and E. R. Steinberg, Ed., Cognitive Processes in Writing, Lawrence Erlbaum Associates, Hillsdale, New Jersey, pps. 31 - 50.

Gregg, L. and Steinberg, E. R. (Ed.), 1880. Cognitive Processes in Writing. Lawrence Erlbaum Associates, Hillsdale, New Jersey.

Haberlandt, K., 1880. "Story grammar and reading time of story constituents." Poetics 8:98- 118 .

Kintsch, W., 1977. Memory and Cognition. John Wiley and Sons, New York.

Kintsch, W., 1980. "Learning from text, levels of comprehension, or: why anyone would read a story anyway." Poetics 9:87 - 88.

Lebowitz, M., 1881. Cancelled due to lack of interest. Proceedings of the Seventh International Joint Conference on Artificial Intelligence, Vancouver, Canada.

Lebowitz, M., 1883. "Memory-based parsing." Artificial Intelligence 21:285 - 326.

Lebowitz, M., 1983. "Generalization from natural language text." Cognitive Science 7:1 $-40$.

Lehnert, W. G., 1981. "Plot units and narrative summarization." Cognitive Science $5: 293 \cdot 332$. 
Mandler, J. M. and Johnson, N. S., 1977. "Remembrance of things parsed: Story structure and recall." Cognitive Psychology 9:111 - 191.

Mandler, J. M. and Johnson, N. S., 1880. "On throwing out the baby with the bathwater: A reply to Black and Wilensky's evaluation of story grammars." Cognitive Science 4:305 - 312 .

McDonald, D. D., 1880. Natural langauge generation as a process of decision making under constraint. Ph.D. Thesis, MIT.

McDonald, D. D. and Conklin, E. J., 1982. Salience as a simplifying metaphor for natural language generation. Proceedings of the Second National Conference on Artificial Intelligence, Pittsburgh, PA, pp. 75 - 78.

McGuire, R., 1980. Political primaries and words of pain. Unpublished manuscript.

McKeown, K. R., 1882. Generating natural language text in response to questions about database structure. Ph.D. Thesis, University of Pennsylvania.

Meehan, J. R., 1876. The metanovel: Writing stories by computer. Technical Report 74, Yale University Department of Computer Science.

Rumelhart, D. E., 1875. Notes on a schema for stories. In D. Bobrow and A. Collins, Ed., Representation and Understanding: Studies in Cognitive Science, Academic Press, New York.

Rumelhart, D. E., 1980. "On evaluating story grammars." Cognitive Science 4:313 -316 .

Schank, R. C., 1975. The structure of episodes in memory. In D. Bobrow and A. Collins, Ed., Representation and Understanding: Studies in Cognitive Science, Academic Press, New York .

Schank, R. C., 1979. "Interestingness: Controlling inference." Artificial Intelligence $12: 273$ - 287 .

Schank, R. C., 1982. Dynamic Memory: A Theory of Reminding and Learning in Computers and People. Cambridge University Press, New York.

Schank, R. C. and Abelson, R. P., 1977. Seripts, Plans, Goals and Understanding. Lawrence Erlbaum Associates, Hillsdale, New Jersey. 
Schank, R. C. and Lebowitz, M., 1978. Does a hippie own a hairdrier? Technical Report 144, Yale University Department of Computer Science.

Schank, R. C., Collins, G. C., Davis, E., Johnson, P. N., Lytinen, S. and Reiser, B. J., 1982. "What's the point." Cognitive Science 6:255 - 276.

Spiro, R. J., 1980. "Prior knowledge and story processing: Integration, selection and variation." Poetics 8:313 - 328.

Stein, N. L. and Glenn C. G., 1979. An analysis of story comprehension in elementary school children. In R. Freedle, Ed., New Directions in Discourse Processing II, Ablex, Norwood, New Jersey.

Thorndyke, P. W., 1877. "Cognitive structures in comprehension and memory of narrative discourse." Cognitive Psychology 8:77 - 110.

Wilensky, R., 1880. Points: A theory of story content. Technical Report M80/17, University of California, Berkeley, Electronic Research Laboratory.

Wilensky, R., 1983. Planning and Understanding. Addison-Wesley, Reading, MA.

Wish, M., Deutsh, M. and Kaplan, S., 1976. "Perceived dimensions of interpersonal relations." Journal of Personality and Social Psychology 33:409 - 420.

Yazdani, M., 1883. Generating events in a fictional world of stories. Technical Report R-113, Computer Science Department, University of Exeter. 